\title{
The clamp-down continues
}

Instances of harassment of Soviet scientists are still coming to light. Vera Rich reports on recent developments

SoviET "refusnik" scientists dismissed from their posts after applying for a visa for Israel have recently been threatened with arrest. An appeal to the world scientific community, signed by Professor Mark Azbel, Viktor Brailovskii and others, states that some 20 scientists called in to regional police headquarters in Moscow were told that if they did not commence working within two weeks they would be charged under the "parasitism" law, which covers such offences as prostitution, drug addiction, and alcoholism.

The illogicality of this demand-it is the authorities who prevent the refusniks finding work-was compounded by the fact that it was also made of the few would-be emigrants, notably Academician Veniamin Levich, who have not yet been dismissed. This suggests that this particular threat is directed at all those scientists who take part in the informal seminars which the refusniks, including Levich, hold to maintain some kind of scientific life and exchange of ideas. For some time, uniformed and plain-clothes police have been making occasional visits to the seminars; these visits have recently been stepped up, and on one occasion a lecturer was interrupted with a demand for identity cards. One seminar, in Kiev, has been closed down by the authorities.

Some idea of the authorities' thinking is also to be found in the recent decision concerning cyberneticists Viktor and Inina Brailovskii. Their original visa applications in 1972 were denied on the grounds that Viktor had had access to classified information. Recently, however, his former superior,

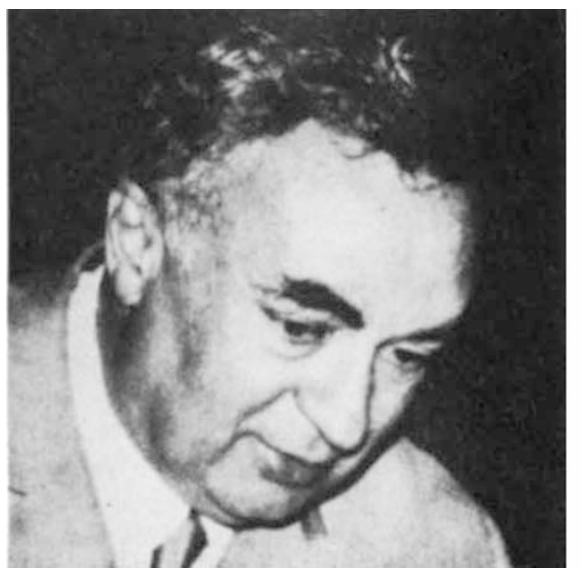

Professor Aleksandr Lunits, was allowed to emigrate to Israel; from there he told the Soviet authorities that since his own security status did not preclude emigration, the same should be true a fortiori of his former subordinate. Viktor Brailovskii has now received clearance, but Irina has been refused, and has been informed that this is specifically on secunity grounds. None of her work at the Moscow University Cybernetics Institute was classified, however, as its publication in open journals proves; and since her dismissal in September 1972, there is no obvious way that she could have acquired secret information.

One possible explanation of this anomaly is contained in a recent statement by Al'bert Ivanov on behalf of the Central Committee of the Communist Party of the Soviet Union. Following complaints that the human rights clauses of the Helsinki agreement were not being implemented, Ivanov gave an interview to six prominent activists, including the scientists Mark Azbel, Vladimar Slepak, and Anatolii Sharanskii. Ivanov said that the "terms of 'secrecy' will themselves remain secret. Things which were not secret yesterday might become secret today, and vice versa". Challenged by Azbel that this implied that someone never connected with secret information might be refused a visa in case his work might possibly become secret in the future, Ivanov replied that this was "possible in principle", since each case was decided individually "in the interests of the State"; he further said that there were not, nor would there ever be, any rules on what constitutes "secrecy" or on how long it takes for such "secrecy" to expire.

In their appeal, the scientists stress that pressure from world opinion can effect at least a temporary relaxation of the authorities" attitude: "Our fate

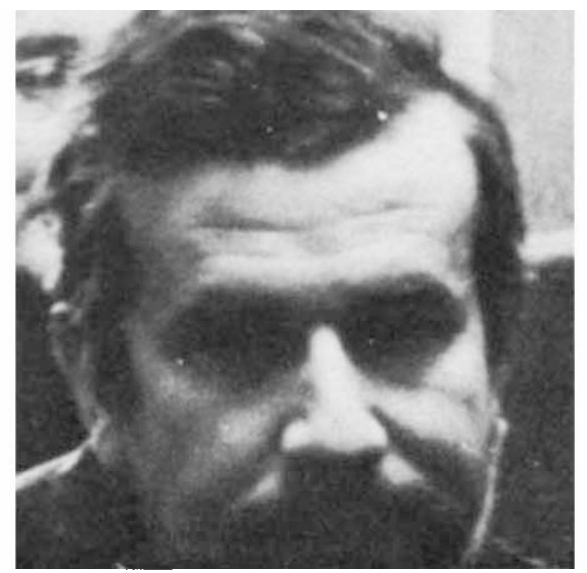

and the fates of our families are in your hands, in the hands of our overseas colleagues", they say. Protests abroad, however, can produce retalitory action, as one recent case has shown.

Professor Brian Spalding, Chairman of the Editorial Board of the International Journal of Heat and Mass Transfer, had been a welcome guest at the first four All-Union Conferences on Heat and Mass Transfer held in Minsk. Since the last Conference in 1972, however, he has been active in the campaign for Academician Veniamin Levich. In November of last year, Professor Spalding received an invitation to the Fifth Conference held last month, and submitted a paper which was accepted. Academician Levich, however, who developed the now standard electrochemical method of determining heat and mass transfer coefficients, was not invited, and on hearing this Professor Spalding protested to the organising committee of the conference. Academician Levich did, finally, receive an invitation, too late to submit a paper; but Professor Spalding was not given a visa to attend, nor was his paper included in the preprints of the conference.

The Fifth Conference was technically an internal Soviet gathering, to which certain foreign guests were invited, and does not technically come under the declaration of the International Council of Scientific Unions on the free circulation of scientists to international conferences. Nevertheless, since Professor Spalding's paper was accepted, the refusal of his visa is being construed as state intervention in the running of the conference. If the case of Professor Spalding was intended as a warning to the world scientific community, it indicates, as Spalding himself has acknowledged, the constant need for a concerted effort to defend the principles of academic freedom, including freedom of movement and communication for all.

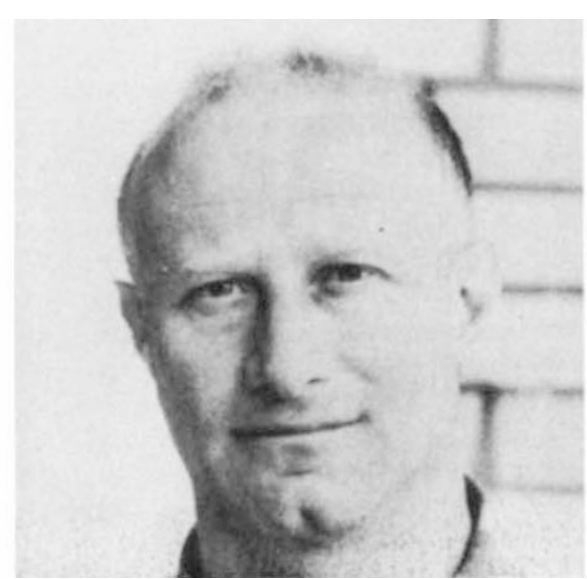

